\title{
Anorectal Infection, CTCAE
}

National Cancer Institute

\section{Source}

National Cancer Institute. Anorectal Infection, CTCAE. NCI Thesaurus. Code C143285.

A disorder characterized by an infectious process involving the anal area and the rectum. 